\title{
Impact of initial exposure to calcineurin inhibitors on kidney graft function of patients at high risk to develop delayed graft function
}

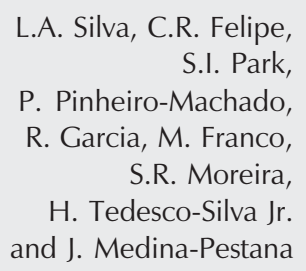

\section{Correspondence}

H. Tedesco-Silva Jr.

Disciplina de Nefrologia

Hospital do Rim e Hipertensão UNIFESP

Rua Borges Lagoa, 960, 119 andar 04038-002 São Paulo, SP

Brasil

Fax: $+55-11-5087-8008$

E-mail: heliotedesco@hrim.com.br

Publication supported by FAPESP.

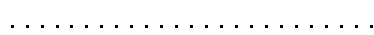

Received July 30, 2004 Accepted October 4, 2005
Disciplina de Nefrologia, Hospital do Rim e Hipertensão, Departamento de Patologia, Universidade Federal de São Paulo, São Paulo, SP, Brasil

\section{Abstract}

We conducted a retrospective analysis of the influence of full doses of calcineurin inhibitors $\left[8-10 \mathrm{mg} \mathrm{kg}^{-1}\right.$ day $^{-1}$ cyclosporine $(\mathrm{N}=80)$, or $0.2-0.3 \mathrm{mg} \mathrm{kg}^{-1}$ day $^{-1}$ tacrolimus $\left.(\mathrm{N}=68)\right]$ administered from day 1 after transplantation on the transplant outcomes of a high-risk population. Induction therapy was used in $13 \%$ of the patients. Patients also received azathioprine $\left(2 \mathrm{mg} \mathrm{kg}^{-1} \mathrm{day}^{-1}\right.$, $\mathrm{N}=58$ ) or mycophenolate mofetil ( $2 \mathrm{~g} /$ day, $\mathrm{N}=90$ ), and prednisone $\left(0.5 \mathrm{mg} \mathrm{kg}^{-1} \mathrm{day}^{-1}, \mathrm{~N}=148\right)$. Mean time on dialysis was 79 \pm 41 months, $12 \%$ of the cases were re-transplants, and $21 \%$ had panel reactive antibodies $>10 \%$. In $43 \%$ of donors the cause of death was cerebrovascular disease and $27 \%$ showed creatinine above $1.5 \mathrm{mg} / \mathrm{dL}$. The incidence of slow graft function (SGF) and delayed graft function (DGF) was 15 and 60\%, respectively. Mean time to last dialysis and to nadir creatinine were $18 \pm 15$ and $34 \pm$ 20 days, respectively. Mean creatinine at 1 year after transplantation was $1.48 \pm 0.50 \mathrm{mg} / \mathrm{dL}$ (DGF $1.68 \pm 0.65$ vs SGF $1.67 \pm 0.66$ $v s$ immediate graft function (IGF) $1.41 \pm 0.40 \mathrm{mg} / \mathrm{dL}, \mathrm{P}=0.089$ ). The incidence of biopsy-confirmed acute rejection was 22\% (DGF $31 \%$, SGF $10 \%$, IGF $8 \%$ ). One-year patient and graft survival was 92.6 and $78.4 \%$, respectively. The incidence of cytomegalovirus disease, post-transplant diabetes mellitus and malignancies was $28,8.1$, and $0 \%$, respectively. Compared to previous studies, the use of initial full doses of calcineurin inhibitors without antibody induction in patients with SGF or DGF had no negative impact on patient and graft survival.

\section{Introduction}

The incidence and duration of the delayed (DGF) and slow graft function (SGF) period after transplantation are risk factors
Key words

- Cyclosporine

- Tacrolimus

- Delayed graft function

- Graft function

- Kidney transplantation 
survival in most studies when compared to recipients of ideal kidneys (2). Preexisting organ lesions, insufficient nephron mass and higher incidence of DGF are variables that may account for these results, although this transplantation with non-ideal kidneys has been associated with a significant patient survival benefit compared to dialysis treatment (3).

Increased time on the waiting list has also been associated with decrease patient and graft survival $(4,5)$. Therefore, transplantation of non-ideal kidneys in patients with long periods on dialysis might be associated with an even inferior transplant outcome. Among many strategies to improve the graft outcome of patients at high risk to develop DGF/SGF is to spare the graft from exposure to early calcineurin inhibitors by using induction protocols with monoclonal or polyclonal antibody preparations (6-8). Although monoclonal preparations of IL-2R blockers are relatively safe, there are still uncertainties about their use without a calcineurin inhibitor in patients at high immunologic risk (9). On the other hand, anti-CD3 and polyclonal preparations have been associated with an increased incidence of infection and death related to lymphoproliferative disorders (10). The impact of induction therapy might be even more remarkable in patients with a long time on the waiting list, who already show significant co-morbidities, altered immunologic function and poor nutrition.

The increased use of non-ideal organs associated with the Brazilian organ allocation system, which is based primarily on time on dialysis, predispose our transplant population to a high risk to develop DGF/ SGF and therefore inferior short- and long-term graft outcome. We present here a retrospective analysis of the use of full doses of calcineurin inhibitors on the incidence of DGF/SGF, acute rejection, graft function, and patient and graft survival at 1 year.

\section{Patients and Methods}

\section{Population}

This was a retrospective study using data collected from 210 cadaver kidney transplants performed between 6/26/2000 and $1 /$ $31 / 2002$. The follow-up study period was 12 months. For this analysis we included all patients who received calcineurin inhibitorbased immunosuppressive therapy. We excluded 34 pediatric patients (aged 17 or less) and 28 patients who were enrolled in other clinical trials with different immunosuppressive agents. The number of patients who participated in the study was 148 .

\section{Immunosuppression}

Patients received cyclosporine (CsA, $\mathrm{N}=80,54 \%$ ) or tacrolimus (TAC, $\mathrm{N}=68$, $46 \%$ ) from day 1 after transplantation. Patients also received azathioprine (AZA, $\mathrm{N}=$ $58,39 \%$ ) or mycophenolate mofetil (MMF, $\mathrm{N}=90,61 \%$ ) as adjunctive therapy and all patients received steroids. The majority of the patients did not receive induction therapy $(87 \%)$. Induction therapy was used in 19 patients (antithymocyte globulin, $\mathrm{N}=2$; orthoclone $3, \mathrm{~N}=11$, and basiliximab, $\mathrm{N}=$ 6). CsA doses were adjusted to achieve target therapeutic trough concentrations of 200 to $400 \mathrm{ng} / \mathrm{mL}$ during the first month, 150 to $300 \mathrm{ng} / \mathrm{mL}$ during the second and third months, and 150 to 250 thereafter. Corresponding TAC trough concentrations were 15 to $20 \mathrm{ng} / \mathrm{mL}$ during the first 2 weeks, 10 to $15 \mathrm{ng} / \mathrm{mL}$ during weeks 3 and 4,8 to 12 $\mathrm{ng} / \mathrm{mL}$ during months 2 and 3 , and 5 to 10 $\mathrm{ng} / \mathrm{mL}$ thereafter. The initial AZA dose was $2 \mathrm{mg} \mathrm{kg}^{-1}$ day $^{-1}$, and the initial dose of MMF was $2 \mathrm{~g} /$ day twice daily. Doses of AZA or MMF were adjusted only according to emerging adverse effects. Initial prednisone doses were $0.5 \mathrm{mg} \mathrm{kg}^{-1}$ day $^{-1}$ with a maximum dose of $30 \mathrm{mg}$ during the first month, tapered to 20 and $10 \mathrm{mg}$ during the second and third 
months, respectively.

DGF was defined as the need for dialysis during the first post-transplant week and SGF as a slow recovery of graft function but no need for dialysis, with creatinine levels higher than $3 \mathrm{mg} / \mathrm{dL}$ by day 7 post-transplant.

A graft biopsy was performed during all suspected episodes of acute rejection and graded according to BANFF 1997 criteria. Mild and moderate acute rejection episodes were treated with a methylprednisone bolus and severe or steroid-resistant rejections were treated with antibodies.

Cytomegalovirus (CMV) disease was defined as a positive antigenemia associated with clinical and/or laboratory abnormalities. Post-transplant diabetes mellitus was defined as the requirement of oral agents or insulin to control glucose concentrations for more than 30 days.

\section{Statistical methods}

All patients were evaluated in an intention to treat analysis during the first 12 months after transplantation. Descriptive statistics were used for all variables. The Student $t$ test was used for continuous demographic variables, vital signs and laboratory determinations. The chi-square test was used to compare the distribution of nominal attributes such as sex and ethnic origin. The rates and histological grade of the first biopsy-confirmed acute rejection episode, any treated acute rejection, acute rejections treated with any antibody preparation, graft loss, death, CMV infection, post-transplant diabetes mellitus, lymphoproliferative disease, and malignancies were compared using the chisquare or the Fisher exact test, depending on the number of events. Blood levels of CsA and TAC are reported as means \pm SD and variability is reported as percent coefficient of variation. All statistical tests were twosided at the 5\% significance level. The 95\% confidence intervals were calculated when possible. Univariate and multivariate analysis was performed using logistic regression analysis to identify risk factors associated with selected transplant outcomes. Results are reported as means \pm SD for continuous variables and as percentages for categorical variables, unless otherwise indicated.

The objectives of the present study were: 1) to determine donor-, recipient- and transplant-related risk factors associated with DGF or SGF; 2) to compare the incidence of DGF or SGF in patients receiving CsA versus TAC; 3) to determine the incidence of biopsy-confirmed acute rejection, any treated acute rejection, and patient and graft survival, 4) to determine graft function at 1 year, and 5) to evaluate selected safety parameters including the incidence of $\mathrm{CMV}$ disease, post-transplant diabetes mellitus, and malignancies.

\section{Results}

\section{Demography}

The demographic characteristics of the recipients are listed in Table 1. Mean age was $42.7 \pm 11.9$ years, $54 \%$ of the patients were males and $49 \%$ were non-whites, including $20.9 \%$ of patients with black ethnicity. About $6.8 \%$ of the patients were diabetic. Mean time on dialysis was $79 \pm 41$ months, ranging from 6 to 280 months. Twelve percent of the patients were receiving a second transplant, and $21 \%$ had current panel reactive antibody (PRA) levels higher than 10\%, and $7 \%$ had PRA levels higher than 50\%. Ninety-nine percent of the patients were CMV IgG positive, and 30 and $12 \%$ tested positive for hepatitis B (HbsAg) and C (anti-HCV), respectively. Mean donor age was $34.1 \pm 12.8$ years $(9 \%$ of the patients were older than 50 years of age). Thirty-three percent of donors were non-white. The most frequent cause of death was cerebrovascular disease (43\%). Vasoactive drugs had been administered to $96 \%$ of donors at the time of organ harvest- 
ing. Ninety-seven percent were multiorgan donors. Mean creatinine at the time of harvesting was $1.35 \pm 0.6 \mathrm{mg} / \mathrm{dL}$ (27\% of donors had creatinine values above $1.5 \mathrm{mg} /$ dL). Mean cold ischemia time was 19.2 \pm 7.8 $\mathrm{h}$, ranging from 5 to $43 \mathrm{~h}$ ( $21 \%$ higher than $24 \mathrm{~h}$ ). Compared to TAC, patients receiving CsA showed lower mean PRA and a higher proportion received kidneys from donors aged more than 50 years and with a cold ischemia time of more than $24 \mathrm{~h}$ (Table 1).

\section{Immunosuppression}

Induction therapy was used in 19 patients mostly due to high-risk criteria, namely, non-white (11), high PRA (19, mean of 27\%, $5>50 \%$ ), and retransplantation (4). Mean CsA and TAC doses and concentrations are shown in Table 2. Relatively high concentrations of CsA or TAC were achieved up to one month after transplantation. Compared to CsA, a higher proportion of patients re-

Table 1. Demographic characteristics of renal transplant recipients and donors.

\begin{tabular}{|c|c|c|c|}
\hline Parameters & Total $(148)$ & $\operatorname{CsA}(N=80)$ & TAC $(N=68)$ \\
\hline Recipient age (years) & $43 \pm 12$ & $42 \pm 12$ & $43 \pm 12$ \\
\hline Recipient gender (male/female) & $\begin{array}{c}79 / 69 \\
(53 \% / 47 \%)\end{array}$ & $\begin{array}{c}45 / 35 \\
(56 \% / 44 \%)\end{array}$ & $\begin{array}{c}34 / 34 \\
(50 \% / 50 \%)\end{array}$ \\
\hline Recipient ethnicity (white/non-white) & $\begin{array}{c}76 / 72 \\
(51 \% / 49 \%)\end{array}$ & $\begin{array}{c}40 / 40 \\
(50 \% / 50 \%)\end{array}$ & $\begin{array}{c}36 / 32 \\
(53 \% / 47 \%)\end{array}$ \\
\hline PRA $(<10 / 10-50 />50 \%)^{\mathrm{a}}$ & $\begin{array}{c}107 / 31 / 10 \\
(72 \% / 21 \% / 7 \%)\end{array}$ & $\begin{array}{c}66 / 10 / 4 \\
(83 \% / 12 \% / 5 \%)\end{array}$ & $\begin{array}{c}41 / 21 / 6 \\
(60 \% / 31 \% / 9 \%)\end{array}$ \\
\hline \multicolumn{4}{|l|}{ Viral status } \\
\hline HbsAg positive & $18(12 \%)$ & $10(12 \%)$ & $8(12 \%)$ \\
\hline HCV IgG positive & $45(30 \%)$ & $28(35 \%)$ & $17(25 \%)$ \\
\hline CMV IgG positive & $146(99 \%)$ & 79 (99\%) & 67 (98\%) \\
\hline \multicolumn{4}{|l|}{ Primary cause of ESRD } \\
\hline Glomerulonephritis & 35 (24\%) & $16(20 \%)$ & $19(28 \%)$ \\
\hline Hypertension & 32 (22\%) & $23(29 \%)$ & $9(13 \%)$ \\
\hline Diabetes mellitus & $10(7 \%)$ & $5(6 \%)$ & $5(7 \%)$ \\
\hline Polycystic kidney disease & $9(6 \%)$ & $3(4 \%)$ & $6(9 \%)$ \\
\hline Others & $62(42 \%)$ & $33(41 \%)$ & $29(43 \%)$ \\
\hline Dialysis type (HD/CAPD) & $\begin{array}{c}140 / 8 \\
(95 \% / 5 \%)\end{array}$ & $\begin{array}{c}76 / 4 \\
(95 \% / 5 \%)\end{array}$ & $\begin{array}{c}64 / 4 \\
(94 \% / 6 \%)\end{array}$ \\
\hline Dialysis time (months) & $79 \pm 41$ & $75 \pm 36$ & $84 \pm 46$ \\
\hline Retransplantation & $17(11 \%)$ & $7(9 \%)$ & $10(15 \%)$ \\
\hline Donor age (years) & $34 \pm 13$ & $34 \pm 14$ & $34 \pm 12$ \\
\hline Donor gender (male/female) & $\begin{array}{c}88 / 60 \\
(59 \% / 41 \%)\end{array}$ & $\begin{array}{c}51 / 29 \\
(64 \% / 36 \%)\end{array}$ & $\begin{array}{c}37 / 31 \\
(54 \% / 46 \%)\end{array}$ \\
\hline Donor ethnicity (white/non-white) & $\begin{array}{c}99 / 49 \\
(67 \% / 33 \%)\end{array}$ & $\begin{array}{c}47 / 33 \\
(59 \% / 41 \%)\end{array}$ & $\begin{array}{c}52 / 16 \\
(76 \% / 24 \%)\end{array}$ \\
\hline \multicolumn{4}{|l|}{ Donor cause of death } \\
\hline Cerebrovascular accident & $64(43 \%)$ & $33(41 \%)$ & 31 (46\%) \\
\hline Head trauma & 62 (42\%) & 31 (39\%) & 31 (46\%) \\
\hline Others & $22(15 \%)$ & $16(20 \%)$ & $6(9 \%)$ \\
\hline Use of vasoactive drugs & $142(96 \%)$ & $76(95 \%)$ & $66(97 \%)$ \\
\hline Donor creatinine $(\mathrm{mg} / \mathrm{dL})$ & $1.3 \pm 0.6$ & $1.3 \pm 0.7$ & $1.4 \pm 0.6$ \\
\hline Cold ischemia time $(h)^{b}$ & $19 \pm 8$ & $21 \pm 8$ & $18 \pm 7$ \\
\hline
\end{tabular}


ceiving TAC also received MMF (38 vs 88\%, $\mathrm{P}<0.001)$. Mean MMF doses were $1.7 \pm 0.4$ and $1.5 \pm 0.4 \mathrm{~g} /$ day at the end of the first month and at 12 months, respectively. Mean AZA doses were $115 \pm 31$ and $96 \pm 32 \mathrm{mg} /$ day at the end of the first month and at 12 months, respectively. Mean prednisone dose was $27 \pm$ $5.4 \mathrm{mg} /$ day at the end of first month, $11.4 \pm 3.4$ $\mathrm{mg} /$ day by month 6 and $9.6 \pm 3.1 \mathrm{mg} /$ day at 12 months. No significant differences were observed in MMF, AZA, or prednisone doses at any time post-transplant between patients receiving CsA and TAC.

\section{Graft function}

Initial graft function was assessed in 145 patients (Table 3 ). Three patients were not included in this analysis because graft loss (venous thrombosis, $\mathrm{N}=2$ ) and death (irreversible intraoperative shock, $\mathrm{N}=1$ ) occurred prior to day 7 post-transplant. Immediate graft function (IGF) was observed in $26 \%$ of the patients (37/145) and was more frequent among patients receiving TAC than among patients receiving CsA (32 vs 20\%, P $=0.52$ ). Impaired initial function was observed in $75 \%$ of the patients. The incidence of SGF was 15\% (21/145), with no significant differences between patients receiving TAC or CsA (15 vs 14\%). The incidence of DGF was $60 \%$ (87/145), and was more frequent among patients receiving CsA compared to TAC (66 vs 53\%, P=0.036). Mean time since the last dialysis was $18 \pm 15$ days and mean time to nadir creatinine was $33.5 \pm$ 19.7 days, with no differences between patients receiving CsA or TAC (Table 3). Recovery from DGF occurred in $84 \%$ of the patients (82\% for CsA and $91 \%$ for TAC, NS). Mean creatinine at 1 year was $1.48 \pm 0.5$ $\mathrm{mg} / \mathrm{dL}$, being lower in patients receiving TAC compared to those receiving CsA (1.42 \pm 0.42 vs $1.74 \pm 0.67 \mathrm{mg} / \mathrm{dL}, \mathrm{P}=0.004)$. At 1 year patients that developed DGF or SGF showed trends towards worse graft function compared with patients with IGF (1.68 \pm
0.65 vs $1.67 \pm 0.66$ vs $1.41 \pm 0.40, \mathrm{P}=0.089$ ).

\section{Efficacy}

There were $32(22 \%)$ episodes of first biopsy-confirmed acute rejections, with 3 (9\%) graded I, 25 (78\%) graded II, and 4 (12\%) graded III according to the Banff criteria (Table 4). There were no differences in the incidence or severity of first biopsyconfirmed acute rejection episodes between patients receiving CsA or TAC. First biopsy-

Table 2. Cyclosporine and tacrolimus doses and blood concentrations.

\begin{tabular}{lccccc}
\hline Visits & \multicolumn{2}{c}{ CsA } & & \multicolumn{2}{c}{ TAC } \\
\cline { 2 - 3 } \cline { 5 - 6 } & $\begin{array}{c}\text { Dose } \\
(\mathrm{mg} / \text { day })\end{array}$ & $\begin{array}{c}\text { Concentration } \\
(\mathrm{ng} / \mathrm{mL})\end{array}$ & & $\begin{array}{c}\text { Dose } \\
(\mathrm{mg} / \text { day })\end{array}$ & $\begin{array}{c}\text { Concentration } \\
(\mathrm{ng} / \mathrm{mL})\end{array}$ \\
\hline Week 1 & $214 \pm 104$ & $532 \pm 126$ & & $18 \pm 5$ & $17 \pm 6$ \\
Week 2 & $296 \pm 139$ & $537 \pm 128$ & & $18 \pm 7$ & $18 \pm 6$ \\
Month 1 & $300 \pm 132$ & $438 \pm 120$ & & $14 \pm 5$ & $14 \pm 6$ \\
Month 2 & $265 \pm 100$ & $353 \pm 124$ & & $11 \pm 5$ & $12 \pm 5$ \\
Month 3 & $216 \pm 85$ & $317 \pm 103$ & & $9 \pm 5$ & $10 \pm 4$ \\
Month 6 & $177 \pm 67$ & $270 \pm 77$ & & $8 \pm 4$ & $9 \pm 3$ \\
Month 12 & $129 \pm 44$ & $145 \pm 65$ & & $3 \pm 2$ & $8 \pm 3$ \\
\hline
\end{tabular}

Data are reported as means \pm SD for 80 patients receiving cyclosporine (CsA) and 68 patients receiving tacrolimus (TAC).

Table 3. Outcome of initial and 1-year graft function.

\begin{tabular}{lccc}
\hline Parameter & Total $(\mathrm{N}=148)$ & CsA $(\mathrm{N}=80)$ & TAC $(\mathrm{N}=68)$ \\
\hline Immediate graft function (IGF) & $26(37 \%)$ & $20(15 \%)$ & $32(22 \%)$ \\
Slow graft function (SGF) & $15(21 \%)$ & $14(11 \%)$ & $15(10 \%)$ \\
Delayed graft function (DGF) & $60(87 \%)$ & $66(51 \%)$ & $53(36 \%)$ \\
Duration of DGF (days) & $18 \pm 15$ & $16 \pm 12$ & $20 \pm 18$ \\
Time to nadir creatinine (days) & $33 \pm 20$ & $33 \pm 21$ & $34 \pm 18$ \\
Creatinine at 1 year (mg/dL) & & & \\
IGF & $1.41 \pm 0.40$ & $1.46 \pm 0.30$ & $1.37 \pm 0.43$ \\
SGF & $(34 \%)$ & $(14 \%)$ & $(20 \%)$ \\
& $1.67 \pm 0.66$ & $1.88 \pm 0.80$ & $1.35 \pm 0.34$ \\
DGFb & $(16 \%)$ & $(8 \%)$ & $(8 \%)$ \\
& $1.68 \pm 0.65$ & $1.81 \pm 0.74$ & $1.48 \pm 0.44$ \\
Total & $(65 \%)$ & $(40 \%)$ & $(25 \%)$ \\
& $1.48 \pm 0.50$ & $1.74 \pm 0.67$ & $1.42 \pm 0.42$ \\
& $(115 \%)$ & $(62 \%)$ & $(53 \%)$
\end{tabular}

Data are reported as means \pm SD and percent in parentheses for patients completing 1 year of follow-up. CsA = cyclosporine $\mathrm{A}$; TAC = tacrolimus.

aP $<0.05$, CsA vs TAC (chi-square test). ${ }^{\text {bP }}<0.05$, CsA vs TAC (Student $t$-test). 
confirmed acute rejection was observed in 27 (31\%), $2(10 \%)$, and $3(8 \%)$ patients with DGF, SGF, and IGF, respectively ( $\mathrm{P}=$ $0.011)$. The incidence of clinically treated acute rejection episodes was $36 \%$ (54/148). Of 22 episodes of presumed acute rejection that were treated with steroids, 9 occurred in patients with borderline changes and 3 in patients with tubulointerstitial nephritis in biopsy specimens, and 10 patients received treatment based on clinical findings only. Twelve patients presented 2 and 1 three acute rejection episodes. Fifteen rejection episodes (10\%), 5 of them (4\%) steroidresistant and $10(7 \%)$ severe acute rejection episodes, required antibody treatment. Compared to TAC, a higher proportion of patients receiving CsA required treatment for acute rejection but the difference did not reach statistical significance (32 vs $42 \%, \mathrm{P}=$ 0.18 ). Changes in the initial immunosuppressive therapy occurred in $25(17 \%)$ patients, mostly after an acute rejection episode. Fourteen patients, 3 in the TAC group and 11 in the CsA group, were switched from AZA to MMF. Nine patients were switched from CsA to TAC and 2 patients in the TAC

Table 4. Efficacy on analysis.

\begin{tabular}{lccc}
\hline Parameter & Total $(\mathrm{N}=148)$ & CsA (N = 80) & TAC (N =68) \\
\hline Biopsy-proven acute rejection & $32(22 \%)$ & $17(21 \%)$ & $15(22 \%)$ \\
IA & $3(9 \%)$ & $3(18 \%)$ & 0 \\
IIA & $18(56 \%)$ & $11(65 \%)$ & $7(47 \%)$ \\
IIB & $7(22 \%)$ & $2(12 \%)$ & $5(33 \%)$ \\
III & $4(12 \%)$ & $1(6 \%)$ & $3(20 \%)$ \\
Treated acute rejection & $54(36 \%)$ & $33(41 \%)$ & $21(31 \%)$ \\
Antibody-treated acute rejection & & & \\
OKT3 & $13(24 \%)$ & $5(15 \%)$ & $8(38 \%)$ \\
ATG & $2(4 \%)$ & $1(3 \%)$ & $1(5 \%)$ \\
Change in immunosuppression & $14(9 \%)$ & $11(14 \%)$ & $3(4 \%)$ \\
AZA $\geq$ MMF & $9(6 \%)$ & $9(11 \%)$ & - \\
CsA $\geq$ TAC* & $2(1 \%)$ & - & $2(3 \%)$ \\
MMF $\geq$ AZA & $21(15 \%)$ & $11(15 \%)$ & $10(15 \%)$ \\
Graft loss & $11(7 \%)$ & $6(7 \%)$ & $5(7 \%)$ \\
Death & & & \\
\hline
\end{tabular}

Data are reported as number of patients (\% of total) CsA = cyclosporine; TAC = tacrolimus; OKT3 = orthoclone $3 ; \mathrm{ATG}=$ antithymocyte globulin; $\mathrm{AZA}=$ azathioprine; MMF = mycophenolate mofetil.

${ }^{*} \mathrm{P}<0.05$, TAC vs CsA (chi-square test). group were switched from MMF to AZA due to adverse gastrointestinal events.

There were 21 graft losses (15\%), 11 deaths $(7.5 \%)$, and one patient was lost to follow-up, with no significant differences comparing between patients receiving CsA or TAC. Causes of graft loss were primary nonfunction $(\mathrm{N}=3,14.3 \%)$, acute rejection $(\mathrm{N}=8,38 \%)$, chronic rejection $(\mathrm{N}=2$, $9.5 \%)$, technical reasons $(\mathrm{N}=6,28.6 \%)$, and others $(\mathrm{N}=2,14.3 \%)$. The incidence of graft loss was 18,10 , and $3 \%$ in patients with DGF, SGF, and IGF, respectively $(\mathrm{P}=0.007)$. Among DGF patients there were $10 \mathrm{graft}$ losses while patients were still on dialysis (vascular thrombosis $(\mathrm{N}=2)$, severe acute rejection $(\mathrm{N}=4)$, renal rupture $(\mathrm{N}=1)$, and primary nonfunction $(\mathrm{N}=3)$ ) and 6 after dialysis was stopped (urological $(\mathrm{N}=1)$, acute rejection $(\mathrm{N}=3)$, chronic rejection $(\mathrm{N}$ $=1)$, and hemolytic-uremic syndrome $(\mathrm{N}=$ 1)). Of 58 patients who did not develop DGF, $3(6 \%)$ lost their graft due to acute rejection, chronic rejection, and vascular complications of renal artery stenosis.

There were 5 deaths $(5.7 \%)$ in patients who developed DGF, 2 while patients were on dialysis and 3 after recovery of graft function. In patients with SGF and IGF we observed $3(14 \%)$ and 2 (5\%) deaths, respectively, and 1 patient died during surgery. The most frequent cause of death was infection (54.4\%). One-year patient and graft survival were 92.6 and $78.4 \%$, respectively. There were no significant differences in patient survival between groups $(\mathrm{DGF}=94.3 \%$ vs $\mathrm{SGF}=85.7 \%$ vs $\mathrm{IGF}=94.5 \%, \mathrm{P}=0.37$ ) or in graft survival $(\mathrm{DGF}=75.9 \%$ vs $\mathrm{SGF}=$ $76.2 \%$ vs IGF $=91.1 \%, \mathrm{P}=0.109)$. Also, there were no significant differences in patient or graft survival between patients receiving CsA or TAC (92.5 vs $92.6 \%$ and 77.5 vs $78 \%$, respectively).

\section{Safety}

The incidence of CMV disease was $28 \%$ 
with no significant differences between patients receiving TAC or CsA (30 vs 26\%). The incidence of post-transplant diabetes mellitus was $8.1 \%$, being more frequent in patients receiving TAC compared to patients receiving CsA (11.8 vs 5\%, $\mathrm{P}=0.12)$. No post-transplant lymphoproliferative disorders or other malignancies were observed up to 12 months after transplantation.

\section{Risk factors}

Since the CsA and TAC groups were not comparable regarding demographic characteristics or initial adjunctive immunosuppressive therapy, univariate analysis was carried out to search for risk factors associated with graft function (graft function after transplant and at 1 year), efficacy (biopsyconfirmed acute rejection, graft loss, or death) and safety parameters (CMV disease and post-transplant diabetes mellitus). These identified risk factors were then used to construct a multivariate analysis to search for independent risk factors. Donor creatinine above $1.1 \mathrm{mg} / \mathrm{dL}(\mathrm{OR}=2.1, \mathrm{CI}=1.0002$ $4.3708, \mathrm{P}=0.05$ ), donor age above 35 years $(\mathrm{OR}=2.2, \mathrm{CI}=1.10-4.5262, \mathrm{P}=0.026)$, and cold ischemia time above $18.3 \mathrm{~h}(\mathrm{OR}=3.1$, $\mathrm{CI}=1.515-6.4167, \mathrm{P}=0.002)$ were independently associated with development of DGF. Donor age above 35 years $(\mathrm{OR}=4.5$, $\mathrm{CI}=1.904-10.5503, \mathrm{P}=0.0006)$, biopsyconfirmed acute rejection $(\mathrm{OR}=2.7, \mathrm{CI}=$ 1.0461-6.9669, $\mathrm{P}=0.04)$, and recipient male sex $(\mathrm{OR}=3.5, \mathrm{CI}=1.5068-8.0321$, $\mathrm{P}=0.0035)$ were independently associated with worse graft function at 1 year (creatinine $>1.4 \mathrm{mg} / \mathrm{dL}$ ). Acute rejection during DGF $(\mathrm{OR}=5.5, \mathrm{CI}=1.87-16.09, \mathrm{P}=$ 0.002 ), creatinine donor above $1.1 \mathrm{mg} / \mathrm{dL}$ $(\mathrm{OR}=2.49, \mathrm{CI}=0.91-6.80, \mathrm{P}=0.07)$ and recipient age above 43 years $(\mathrm{OR}=3.29$, $\mathrm{CI}=1.19-9.10, \mathrm{P}=0.02)$ were independently associated with duration of DGF ( $>14$ days).

Risk factors (Table 5) associated with biopsy-confirmed acute rejection were DGF $(\mathrm{OR}=4.3, \mathrm{CI}=1.8547-9.9973, \mathrm{P}=0.0007)$ and re-transplant $(\mathrm{OR}=4.5, \mathrm{CI}=1.4337$ $13.8858, \mathrm{P}=0.0098)$. Receptor age above 43 years $(\mathrm{OR}=0.5, \mathrm{CI}=0.2172-0.9949, \mathrm{P}=$ $0.048)$ and use of MMF (OR $=0.5, \mathrm{CI}=$ $0.2105-1.0037, \mathrm{P}=0.05$ ) were independent protective variables. Donor creatinine above $1.1 \mathrm{mg} / \mathrm{dL}(\mathrm{OR}=6.1, \mathrm{CI}=1.4875-24.7414$, $\mathrm{P}=0.019)$, DGF $(\mathrm{OR}=3.7, \mathrm{CI}=1.0897$ 12.9710, $\mathrm{P}=0.036$ ), and male recipients of female organs $(\mathrm{OR}=6.6, \mathrm{CI}=2.1479$ $20.2823, \mathrm{P}=0.001)$ were independently associated with graft loss at 1 year. The only variable associated with $\mathrm{CMV}$ infection was any treated acute rejection $(\mathrm{OR}=6.3, \mathrm{CI}=$ 2.8861-13.8293, $\mathrm{P}<0.001)$. We did not detect any risk factor associated with posttransplant diabetes mellitus.

Table 5. Risk factors associated with graft function, efficacy and safety parameters.

\begin{tabular}{|c|c|c|c|}
\hline Parameter & OR & $95 \% \mathrm{Cl}$ & $\mathrm{P}$ \\
\hline \multicolumn{4}{|l|}{ Graft function } \\
\hline \multicolumn{4}{|l|}{ DGF } \\
\hline Donor creatinine $(>1.1 \mathrm{mg} / \mathrm{dL})$ & 2.1 & $1.00-4.37$ & 0.05 \\
\hline Donor age (>35 years) & 2.2 & $1.10-4.56$ & 0.026 \\
\hline Cold ischemia time $(>18.3 \mathrm{~h})$ & 3.1 & $1.51-6.41$ & 0.002 \\
\hline \multicolumn{4}{|l|}{ Duration of DGF ( $>14$ days) } \\
\hline Acute rejection during DGF & 5.5 & $1.87-16.09$ & 0.002 \\
\hline Donor creatinine $(>1.1 \mathrm{mg} / \mathrm{dL})$ & 2.5 & $0.91-6.80$ & 0.07 \\
\hline Receptor age ( $>43$ years) & 3.3 & $1.19-9.10$ & 0.02 \\
\hline \multicolumn{4}{|l|}{ Creatinine at 1 year $(>1.4 \mathrm{mg} / \mathrm{dL})$} \\
\hline Donor age (>35 years) & 4.5 & $1.90-10.55$ & 0.0006 \\
\hline Biopsy-proven acute rejection & 2.7 & $1.05-6.97$ & 0.04 \\
\hline Recipient sex (male) & 3.5 & $1.51-8.03$ & 0.0035 \\
\hline \multicolumn{4}{|l|}{ Efficacy } \\
\hline \multicolumn{4}{|l|}{ Biopsy-proven acute rejection } \\
\hline DGF & 4.3 & $1.85-9.99$ & 0.0007 \\
\hline Retransplant & 4.5 & $1.43-13.88$ & 0.0098 \\
\hline Receptor ( $>43$ years) & 0.5 & $0.21-0.99$ & 0.048 \\
\hline Use of MMF & 0.5 & $0.21-1.00$ & 0.05 \\
\hline \multicolumn{4}{|l|}{ Graft loss } \\
\hline Donor creatinine (>1.1 mg/dL) & 6.1 & $1.49-24.74$ & 0.019 \\
\hline DGF & 3.7 & $1.09-12.97$ & 0.036 \\
\hline Male recipients of female organs & 6.6 & $2.15-20.28$ & 0.001 \\
\hline \multicolumn{4}{|l|}{ Safety parameters } \\
\hline \multicolumn{4}{|l|}{$\mathrm{CMV}$ disease } \\
\hline Any treated acute rejection & 6.3 & $2.88-13.83$ & 0.001 \\
\hline
\end{tabular}

The risk factors were associated significantly $(P<0.05)$ with graft function, efficacy and safety parameters. OR = odds ratio; $95 \% \mathrm{Cl}=95 \%$ confidence interval; DGF = delayed graft function; MMF = mycophenolate mofetil; CMV = cytomegalovirus. 


\section{Discussion}

The initial use of calcineurin inhibitors, regardless of allograft initial function, is still controversial. Increased incidence and prolonged duration of DGF have been reported using this immunosuppressive strategy, with negative impact on long-term graft function and survival. The demographic characteristics of our population (Table 1) are associated with increased risk to develop DGF/ SGF and inferior short- and long-term transplant outcomes (11-13). The majority of the transplanted kidneys probably met the expanded donor criteria and $95 \%$ of the patients had been on dialysis for more than 24 months, risk factors independently associated with development of DGF $(14,15)$ and with inferior renal transplant outcomes (5). The incidence and duration of DGF observed in this study stand out when compared to previous studies and with UNOS data $(11,16)$.

The ideal immunosuppressive regimen for this population has not yet been defined (1). Induction therapy was used in only $13 \%$ of patients who showed additional immunological risk factors at the time of transplantation. There were many reasons justifying the low use of induction therapy. Anti-lymphocyte antibody induction therapy is associated with a significant relative risk for patient death secondary to cardiovascular causes and infectious complications early during the post-transplant period (10). Antibodies directed at IL-2R lack consistent data showing good efficacy in high-risk patients $(1,9)$. Among 19 patients considered to be at higher risk and who received antibodies, 13 (68\%) developed DGF, 7 (37\%) presented acute rejection, $3(16 \%)$ lost their grafts, and $3(16 \%)$ died. These results agree with previous reports of an immune-mediated basis for DGF $(1,17)$ and, in this setting, a higher risk of developing acute rejection, early graft loss and death $(12,17,18)$.

All patients received calcineurin inhibitors within $24 \mathrm{~h}$ after graft revascularization and $75 \%$ of the patients developed DGF or SGF. Since there was no control group, with delayed introduction of calcineurin inhibitors, it is difficult to establish a direct relationship between calcineurin inhibitor use and increased incidence of DGF/SGF. However, $74 \%$ did not show a significant drop in creatinine (>20\%) up to $48 \mathrm{~h}$ after transplantation (19). Risk factors associated with the incidence of DGF were donor age $(\mathrm{OR}=$ $2.2)$, donor creatinine $(\mathrm{OR}=2.1)$ and cold ischemia time $(\mathrm{OR}=3.1)$. Calcineurin inhibitor concentrations were at or above the upper limit of the predetermined therapeutic concentrations, especially during the first 6 months (Table 2), and might be associated with the long duration of the DGF period (20,21). Biopsy-confirmed acute rejection $(\mathrm{OR}=5.5)$, donor creatinine $(\mathrm{OR}=2.5)$ and recipient age $(\mathrm{OR}=3.3)$ were independently associated with a prolonged DGF period (>14 days). Overall, 75 (86\%) patients who developed DGF recovered graft function, with the occurrence of 7 graft losses, 3 cases of primary nonfunction, and 2 deaths during the DGF period.

These high calcineurin inhibitor blood concentrations might also be associated with the relatively low incidence of biopsy-confirmed acute rejection (24\%), considering the high-risk characteristics of this transplant population. Acute rejection was more frequent among patients who developed DGF, and independent risk factors associated with biopsy-confirmed acute rejection were DGF and retransplantation. Recipient age above 43 years $(\mathrm{OR}=0.5)$ and use of MMF $(\mathrm{OR}=0.5)$ were protective factors (22).

One-year patient $(92.6 \%)$ and graft survival $(78.4 \%)$ were comparable to UNOS data (23). Patients with either DGF or SGF showed a $15 \%$ reduction in graft survival at 1 year, which was not significantly different from IGF patients, perhaps due to the small sample size. Risk factors associated with graft loss were donor creatinine $(\mathrm{OR}=6.1)$, 
male recipients of female organs $(\mathrm{OR}=6.6)$ and incidence $(\mathrm{OR}=3.7)$, but not duration, of DGF.

As demonstrated in other studies, there was a trend towards better graft survival in patients with IGF compared with patients with SGF/DGF (Table 3), although neither incidence nor duration of DGF $(14,17,24,25)$ were independently associated with graft function at 1 year (Table 5). Impaired graft function at 1 year was associated with donor age above 35 years $(\mathrm{OR}=4.5)$, biopsyconfirmed acute rejection $(\mathrm{OR}=2.7)$, and recipient male sex $(\mathrm{OR}=3.5)$.

Data on the effect of SGF, DGF, duration of DGF, and acute rejection on 1-year graft function and patient and graft survival are conflicting. Some studies have demonstrated that DGF reduces graft survival independent of acute rejection $(11,12,15,23)$ and others that DGF affects graft function but not survival (14,17,24-26). Most studies have shown that acute rejection has at least an additive effect on the impact of SGF/DGF on graft survival. Prolonged DGF for more than 6 to 8 days has been associated with inferior long-term graft outcome (27-29). DGF has also been associated with short-term inferior patient survival $(18,30)$. Altogether, our data confirm the contribution of immunological and non-immunological risk factors to graft function and survival (1).

The low incidence and severity of CMV disease as well as the absence of malignancies observed during the first year underscore the safety of this strategy. Only treated acute rejection was associated with the incidence of CMV disease. Risk factors associated with hospitalizations due to CMV disease were time on dialysis equal to or longer than 6 months, MMF therapy and allograft rejection (31). The low prevalence of donorpositive and recipient-negative $\mathrm{CMV} \operatorname{IgG}$ seropositivity and the low use of antibody induction might be involved since none of the patients received CMV prophylaxis. The incidence of post-transplant diabetes mellitus was low, taking into account the demographic characteristics of the transplant population and the relatively high concentration of calcineurin inhibitors used, especially TAC for which concentrations above $15 \mathrm{ng} / \mathrm{mL}$ early after transplantation have been associated with a higher incidence of post-transplant diabetes mellitus (32).

The projected kidney transplant scenario for the future suggests that an increased number of transplants will be performed in patients with longer time on dialysis receiving organs retrieved from the expanded donor pool. Moreover, due to the length of the DGF phase, it would also be difficult to decide when to stop antibody use and to begin calcineurin inhibitors due to the long DGF period these patients showed. The use of full-dose CsA without antibody induction and irrespective of initial graft function may still be a safe and effective therapeutic option (33). An attractive alternative described recently would include the use of anti-IL-2R antibodies and reduced doses of calcineurin inhibitors. However, this strategy needs to be tested in a high-risk transplant population $(8,34)$.

\section{References}

1. Halloran PF \& Hunsicken LG (2001). Delayed graft function: state of the art. American Journal of Transplantation, 1: 115-120.

2. Cosio FG, Qiu W, Henry ML et al. (1996). Factors related to the donor organ are major determinants of renal allograft function and survival. Transplantation, 62: 1571-1576.

3. Ojo AO, Hanson JA, Meier-Kriesche $\mathrm{H}$ et al. (2001). Survival in recipients of marginal cadaveric donor kidneys compared with other recipients and wait-listed transplant candidates. Journal of the American Society of Nephrology, 12: 589-597.

4. Meier-Kriesche HU, Port FK, Ojo AO et al. (2000). Effect of waiting time on renal transplant outcome. Kidney International, 58: 13111317.

5. Meier-Kriesche HU \& Kaplan B (2002). Waiting time on dialysis as the strongest modifiable risk factor for renal transplant outcomes. 
Transplantation, 74: 1377-1381.

6. Grinyo JM, Gil-Vernet S, Cruzado JM et al. (2003). Calcineurin inhibitor-free immunosuppression based on antithymocyte globulin and mycophenolate mofetil in cadaveric kidney transplantation: results after 5 years. Transplant International, 16: 820-827.

7. Gonwa T, Johnson C, Ahsan N et al. (2003). Randomized trial of tacrolimus + mycophenolate mofetil or azathioprine versus cyclosporine + mycophenolate mofetil after cadaveric kidney transplantation: results at three years. Transplantation, 75: 2048-2053.

8. Chang GJ, Mahanty HD, Vincenti $F$ et al. (2000). A calcineurin inhibitor-sparing regimen with sirolimus, mycophenolate mofetil, and anti-CD25 mAb provides effective immunosuppression in kidney transplant recipients with delayed or impaired graft function. Clinical Transplantation, 14: 550-554.

9. Hong JC \& Kahan BD (2001). A calcineurin antagonist-free induction strategy for immunosuppression in cadaveric kidney transplant recipients at risk for delayed graft function. Transplantation, 71: 1320-1328.

10. Meier-Kriesche HU, Arndorfer JÁ \& Kaplan B (2002). Association of antibody induction with short and long-term cause specific mortality in renal transplant recipients. Journal of the American Society of Nephrology, 13: 769-772.

11. Koning OH, Ploeg RJ, van Bockel JH et al. (1997). Risk factors for delayed graft function in cadaveric kidney transplantation: a prospective study of renal function and graft survival after preservation with University of Wisconsin solution in multi-organ donors. Transplantation, 63: 1620-1628.

12. Ojo AO, Wolfe RA, Held PJ et al. (1997). Delayed graft function: Risk factors and implications for renal allograft survival. Transplantation, 63: 968-974.

13. Humar A, Johnson EM, Payne WD et al. (1997). Effect of initial slow graft function on renal allograft rejection and survival. Clinical Transplantation, 11: 623-627.

14. Marcen R, Orofino L, Pascual J et al. (1998). Delayed graft function does not reduce the survival of renal transplant allografts. Transplantation, 66: 461-466.

15. McLaren AJ, Jassem W, Gray DW et al. (1999). Delayed graft function: risk factors and the relative effects of early function and acute rejection on long-term survival in cadaveric renal transplantation. Clinical Transplantation, 13: 266-272.

16. Gjertson DW (2000). Impact of delayed graft function and acute rejection on kidney allograft survival. Clinical Transplants, 467-480.

17. Boom H, Mallat MJ, de Fijter JW et al. (2000). Delayed graft function influences renal function, but not survival. Kidney International, 58: 859-866.

18. Gill JS \& Pereira BJ (2003). Death in the first year after kidney transplantation: implications for patients on the transplant waiting list. Transplantation, 75: 113-117.

19. Govani MV, Kwon O, Batiuk TD et al. (2002). Creatinine reduction ratio and 24-hour creatinine excretion on post transplant day two: simple and objective tools to define graft function. Journal of the American Society of Nephrology, 13: 1645-1649.

20. Novick AC, Hwei HH, Steinmuller D et al. (1986). Detrimental effect of cyclosporine on initial function of cadaver renal allografts follow- ing extended preservation. Results of a randomized prospective study. Transplantation, 42: 154-158.

21. Matas AJ, Tellis VA, Quinn TA et al. (1988). Individualization of immediate post-transplant immunosuppression. The value of antilymphocyte globulin in patients with delayed graft function. Transplantation, 45: 406-409.

22. Arnold AN, Wombolt DG, Whelan TV et al. (2000). Mycophenolate mofetil, with cyclosporine and prednisone, reduces early rejection while allowing the use of less antilymphocytic agent induction and cyclosporine in renal recipients with delayed graft function. Clinical Transplantation, 14: 421-426.

23. Shoskes DA \& Cecka JM (1998). Deleterious effects of delayed graft function in cadaveric renal transplant recipients independent of a rejection. Transplantation, 66: 1697-1701.

24. Humar A, Ramcharan T, Kandaswamy R et al. (2002). Risk factors for slow graft function after kidney transplants: a multivariate analysis. Clinical Transplantation, 16: 425-429.

25. Park JH, Yang CW, Kim YS et al. (2002). Comparisons of clinocopathological correlations between immediate and slow graft function in renal transplant recipients. Clinical Transplantation, 16 (Suppl 8): 18-23.

26. Troppmann C, Gillingham KJ, Gruessner RW et al. (1996). Delayed graft function in the absence of rejection has no long-term impact. A study of cadaver kidney recipients with good function at one year after transplantation. Transplantation, 61: 1331-1337.

27. Yokoyama I, Uchida K, Kobayashi T et al. (1994). Effect of prolonged delayed graft function on long-term graft outcome in cadaveric kidney transplantation. Clinical Transplantation, 8: 101-106.

28. Fernandez-Juarez G, Marcen R, Pascual J et al. (2002). Prolonged delayed graft function decreases graft survivals in transplant patients taking cyclosporine. Transplantation Proceedings, 34: 338339.

29. Giral-Classe M, Hourmant M, Cantarovich D et al. (1998). Delayed graft function of more than six days strongly decreases long-term survival of transplanted kidneys. Kidney International, 54: 972-978.

30. Woo YM, Jardine AG, Clark AF et al. (1999). Early graft function and patient survival following cadaveric renal transplantation. Kidney International, 55: 692-699.

31. Abbott KC, Hyppolite IO, Viola R et al. (2002). Hospitalizations for cytomegalovirus disease after renal transplantation in the United States. Annals of Epidemiology, 12: 402-409.

32. Maes BD, Kuypers D, Messiaen T et al. (2001). Post-transplantation diabetes mellitus in FK506-treated renal transplant patients: Analysis of incidence and risk factors. Transplantation, 72: 1655-1661.

33. Douzdjian V, Bhaskar S, Baliga PK et al. (1997). Graft outcome in cadaver renal transplants treated with full-dose cyclosporine induction without antibody, irrespective of graft function. Clinical Transplantation, 11: 294-298.

34. Gonwa TA, Mai ML, Smith LB et al. (2002). Immunosuppression for delayed or slow graft function in primary cadaveric renal transplantation: use of low dose tacrolimus therapy with post-operative administration of anti-CD25 monoclonal antibody. Clinical Transplantation, 16: 144-149. 